\title{
INFLUENCE OF ISOLATED CLEFT PALATE AND PALATOPLASTY ON THE FACE
}

\author{
Omar Gabriel da SILVA FILHO ${ }^{1}$, Larissa Alves de Albuquerque ROSA², Rita de Cássia M. Carvalho LAURIS ${ }^{3}$
}

1-DDS, MSc, Orthodontist, Hospital for Rehabilitation of Craniofacial Anomalies, USP, Bauru, SP, Brazil.

2-DDS, Graduate student in Orthodontics, Hospital for Rehabilitation of Craniofacial Anomalies, USP, Bauru, SP, Brazil.

3-DDS, MSc, Orthodontist, Hospital for Rehabilitation of Craniofacial Anomalies, USP, Bauru, SP, Brazil.

Corresponding address: Omar Gabriel da Silva Filho - Setor de Ortodontia do Hospital de Reabilitação de Anomalias Craniofaciais da USP Rua: Silvio Marchione, 3-20 Vila Universitária - 17012-900 - Bauru - SP - e-mail: ortoface@travelnet.com.br - Phone: $55143234-3348$

Received: October 18, 2006 - Modification: March 09, 2007 - Accepted: April 11, 2007

\begin{abstract}
I

$I_{\text {ntro }}$

literature has demonstrated that alterations in craniofacial morphology characterizing individuals with chered in both operated and unoperated patients. Objective. This study evaluated the influence of isolated cleft palate and palatoplasty on the face, based on facial analysis. Material and methods. Lateral facial photographs of the right side of 85 young adult patients with cleft palate were analyzed, of whom 50 were operated on and 35 had never received any previous surgical treatment. The nasolabial angle and zygomatic projection were used to define the maxillary position in the face. Mandibular positioning was classified as Pattern I, II and III. Results. Patients were distributed into 54.12\% as Pattern I, 32.94\% Pattern II and 12.94\% Pattern III. Distribution of facial patterns did not show statistically significant differences between groups $(\mathrm{p}>0.05)$. Although palatoplasty did not influence the facial pattern, the zygomatic projection was vulnerable to plastic surgeries. Twenty-eight percent of the patients in the operated group showed zygomatic deficiency, compared to only $8.5 \%$ in the unoperated group. Conclusions. In patients with isolated cleft palate, palatoplasty may influence negatively the sagittal behavior of the maxilla, according to the zygomatic projection of the face, though without compromising the facial pattern.
\end{abstract}

Uniterms: Cleft lip; Cleft palate; Surgery; Face.

\section{INTRODUCTION}

The isolated cleft palate with different extents (Figure 1) accounts for nearly $23 \%$ of all clefts affecting mankind and is more frequent in females ${ }^{7}$. A large number of authors believe in the extra-genetic etiology of cleft palate, even though it has been reported that several genes are involved in formation of the palate $2,13,18,22,29$.

It is clinically distinguished from clefts affecting the primary palate because it does not affect the alveolar ridge and perioral musculature. This does not allow diagnosis of the cleft by facial analysis, since it is hidden in the palate (Figures 1 and 2).

The sequels inherent to rupture of the speech articulatory tube refer to the nasal quality of voice, colloquially known as scrannel voice, and hearing impairment. Regardless of the anatomical extent, interdisciplinary rehabilitation involves surgical repair (Figure 2) and speech therapy for anatomical recovery and subsequent functional adaptation. The Hospital for Rehabilitation of Craniofacial Anomalies of the University of São Paulo (HRAC/USP - Bauru, SP, Brazil) has established a therapeutic routine with accomplishment of palatoplasty at 12 months of age. It seems axiomatic to recompose the morphology and then search for adequacy of functions developed by the nasopharyngeal system ${ }^{19,21}$. Anatomical restoration of isolated cleft palate aims at the achievement of normal speech development, protection of respiratory nasal mucosa and better functioning of the auditory tube. It is consensual that the earlier the palatoplasty, the better the functional responses ${ }^{12,16}$.

Two factors interfere with the final dentofacial configuration of the patient with cleft lip and palate, namely the presence of the cleft and the therapeutic interference primarily represented by plastic surgeries. It is generally accepted that primary plastic surgeries performed at conventional periods in childhood induce different morphological facial alterations not always favorable along facial growth, in the different types of cleft. In complete cleft lip and palate, the long-term changes induced by primary plastic surgeries (Figure 3), especially cheiloplasty, restrict the growth of the midface to variable extents ${ }^{5,7}$. Basically, it could be considered that this deleterious effect is directly and strictly related to the degree of trauma induced 
and number of surgeries performed at early ages. In complete cleft lip and alveolus, unlike the cases of complete cleft lip and palate, the postoperative morphological changes usually favor the normal development of the maxilla and maxillary dental $\operatorname{arch}^{28}$ (Figure 4). In isolated cleft palate, the cleft itself, as well as palatoplasty, does not seem to affect significantly the maxilla ${ }^{26}$.

The configuration of dentofacial characteristics of patients with cleft lip and palate has been established on the basis of cephalometrics. Within this context, the cephalometric pattern of patients with isolated cleft palate presents a difference compared to cephalometric norms. Patients with unoperated cleft palate present proportionally smaller cranial base length (S-N), maxillary length (ANSPNS) and mandibular length (Go-Gn), with statistically significant differences, establishing an acceptable anteroposterior relationship between the maxilla and mandible (ANB nearly $\left.1.5^{\circ}\right)^{4,9,25}$. This satisfactory sagittal relationship is followed by vertical facial growth because the mandibular structural morphology favors clockwise rotation. It is also suggested that this mandibular clockwise rotation masks the smaller sagittal participation of the maxilla in the face. Thus, it may be concluded that this difference in the cephalometric pattern is influenced by the cleft.

Comparison of the cephalometric pattern between operated and unoperated patients reveals lack of significant differences in all cephalometric measurements, with similar

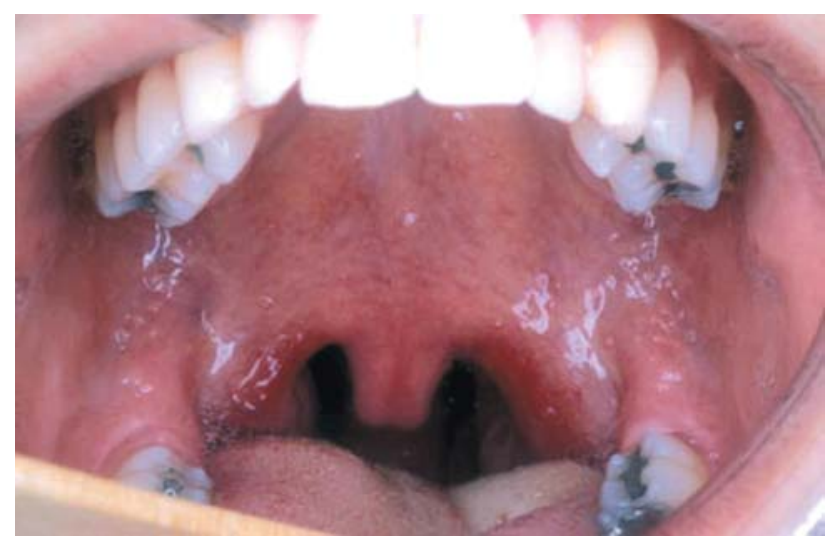

A

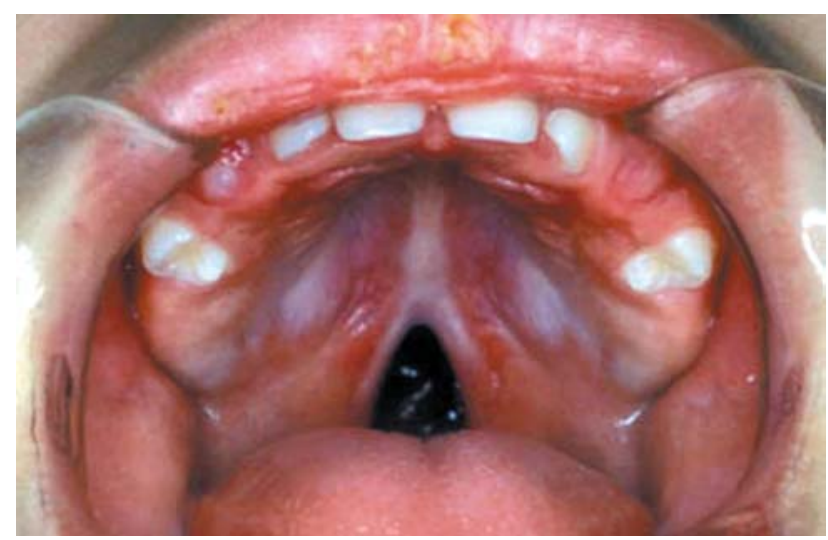

C values $^{1,9,26}$. This similarity demonstrates that both operated and unoperated patients present similar facial morphology, which is different from the normative pattern, reducing the late surgical consequences of participation in final facial configuration, regardless of the surgical technique employed $^{3}$. Figure 5 illustrates the occlusal and facial characteristics of an adult patient with isolated cleft palate not previously treated. Evaluation of the face and occlusion does not allow assuming that the patient has cleft palate or has not been submitted to palate surgery. Therefore, it may be concluded that the dentofacial morphology defined by cephalometrics in patients with isolated cleft palate is inherent to the individual and not influenced by palatoplasty. The immutability of the maxilla is maintained even after accomplishment of pharyngoplasty, at 6 years of age ${ }^{11}$. The influence of the palatoplasty technique has been limited to the transverse development of the maxillary dental $\operatorname{arch}^{2,14}$.

The general literature corroborates that alterations in craniofacial morphology characterizing individuals with cleft palate are observed both in operated and unoperated patients, even though it has been suggested that accomplishment of palatoplasty at early ages may favorably reorientate the facial growth pattern, reducing the mandibular vertical rotation with consequent reduction in mandibular plane inclination and anterior facial height, increasing the forward projection of the mandible ${ }^{9}$.

In order to evaluate the influence of cleft palate and

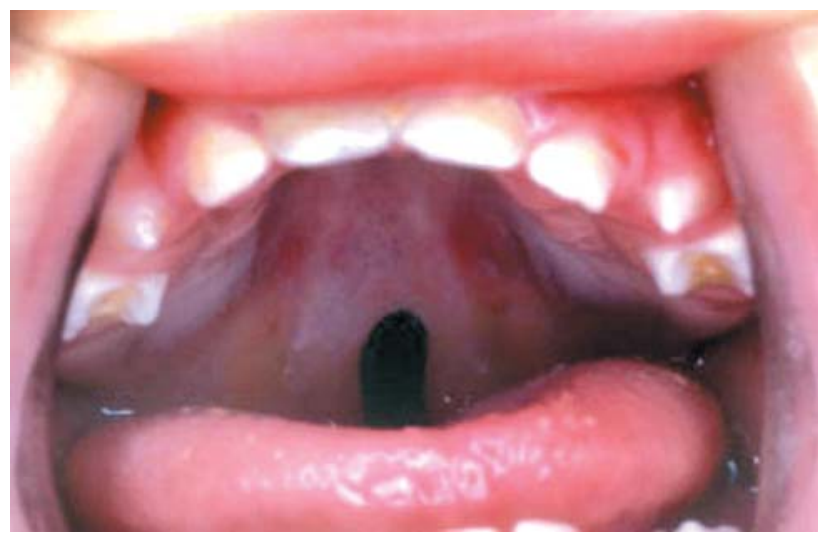

B

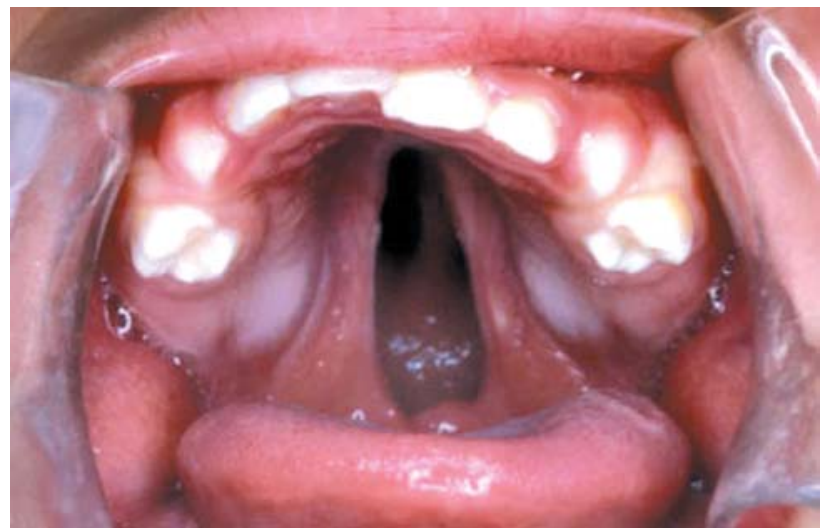

D

FIGURE 1- Different extents of isolated cleft palate: A) uvula, B) soft palate, C) incomplete hard palate and D) complete hard palate 


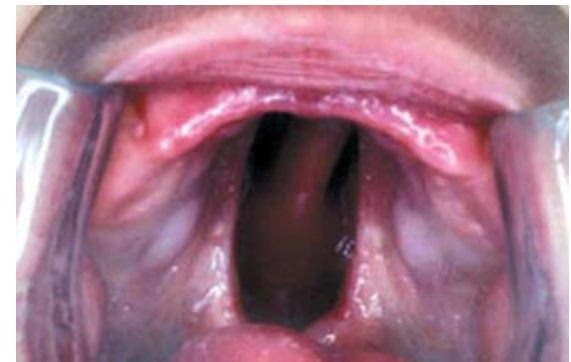

A

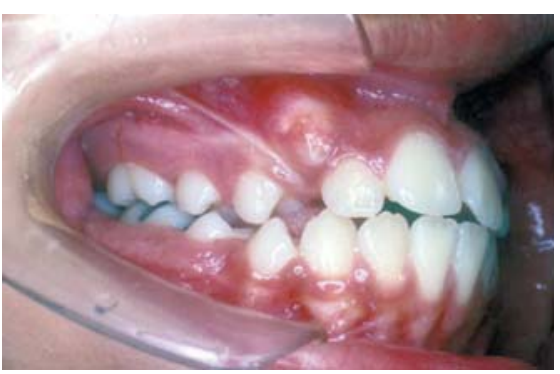

D

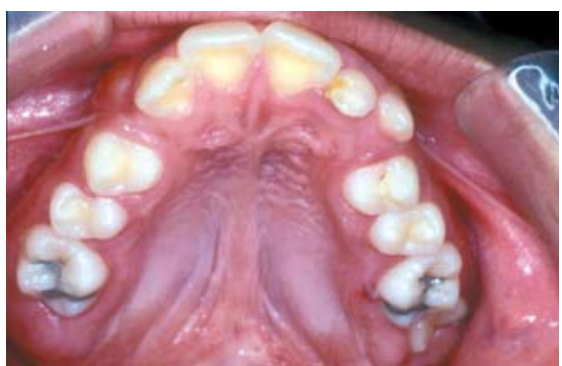

G

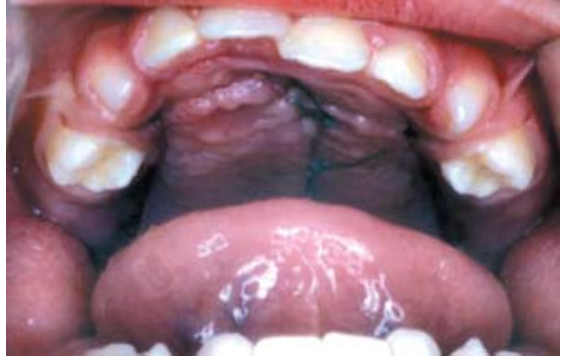

B

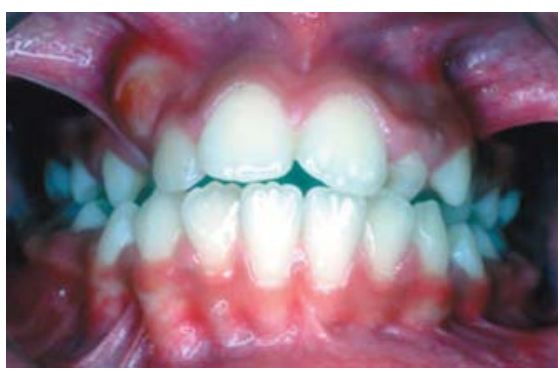

E

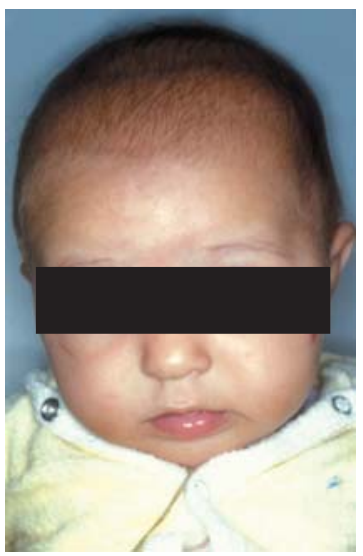

H

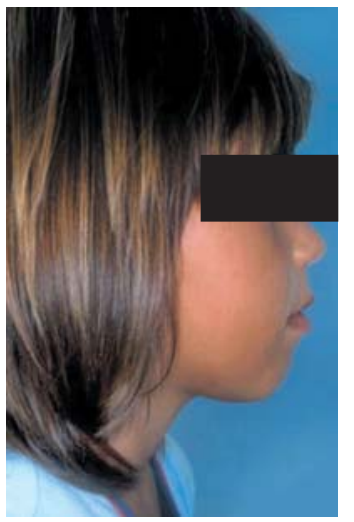

M

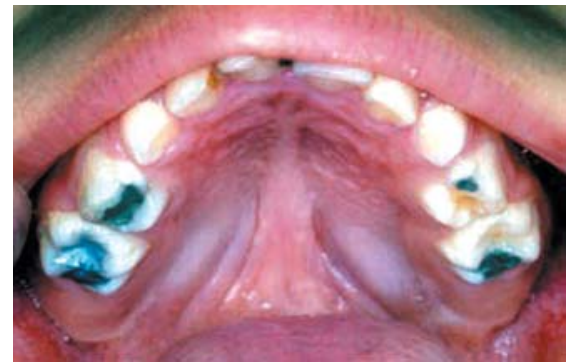

C

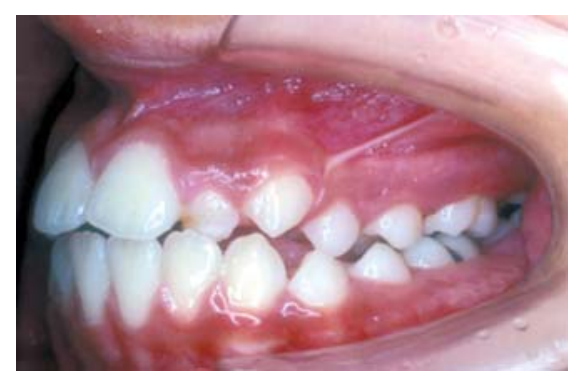

F

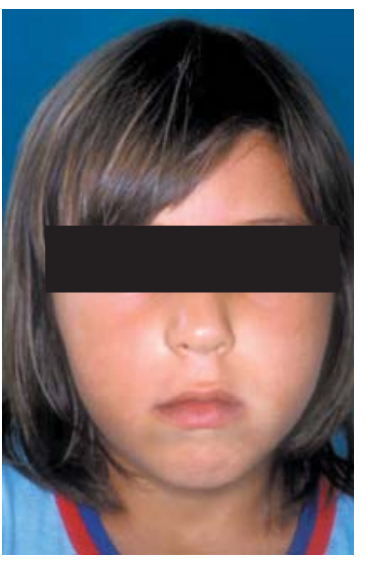

I

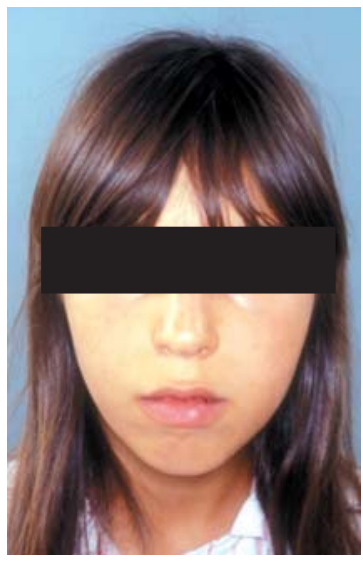

J

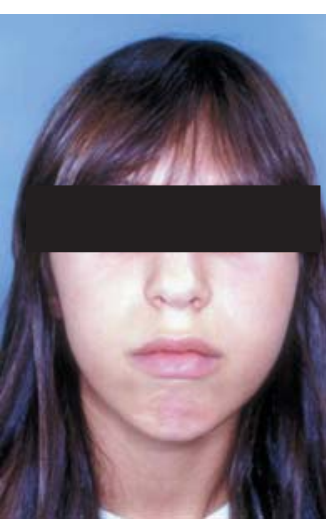

K

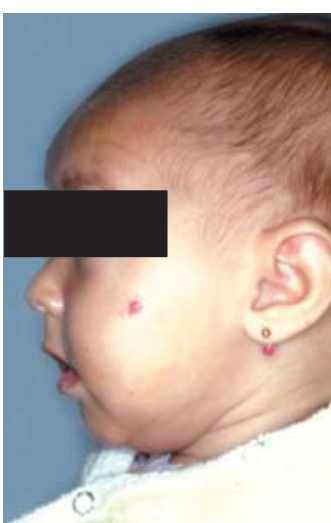

L

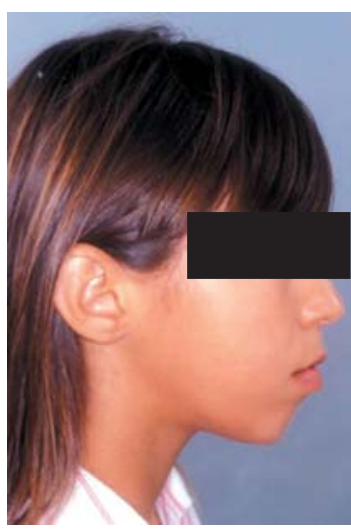

N

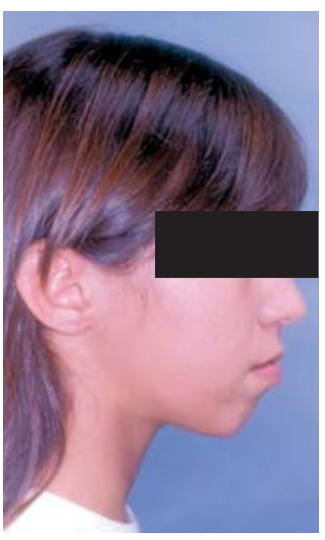

O

FIGURE 2- Patient with complete cleft palate. Photographs showing the diagnosis, plastic surgery and spontaneous development of occlusion and face. A) complete cleft palate (soft and hard palate), B) palatoplasty at 2 years of age for reconstruction of the palatal mucosa, C) integrity of palatal mucosa after palatoplasty. D) to G) intraoral views at 12 years of age, $\mathrm{H}$ ) to O) frontal and lateral facial views at 4 months, 4, 10 and 12 years of age 
palatoplasty on the face, the present study established the maxillary position in the face, by evaluation of the nasolabial angle and zygomatic projection, and evaluated the mandibular position by analysis of facial pattern.

\section{MATERIALAND METHODS}

The research protocol was first reviewed and approved by the HRAC/USP Institutional Review Board.

The study population was composed of 85 postadolescent Brazilian patients registered at HRAC/USP, being 63 females and 22 males, who presented complete and incomplete cleft palate (Table 1 ). The patients were aged 13 years to 46 years and 5 months, with mean age of 26 years and 2 months. Among the 85 patients, 50 had been previously submitted to palatoplasty (Von Langenbeck palatal closure), and 35 had not. Patients had not been submitted to orthodontic treatment and were randomly and consecutively enrolled in the study as they attended the hospital for diagnosis (unoperated patients) or follow up (operated patients). The hospital records of operated patients were used for confirmation of data on the treatment provided at HRAC/USP.

Lateral facial photographs (right side) were taken of patients with a digital camera adapted to an articulated metal support attached to the wall by a wooden support. Patients were positioned standing, stabilized by a metal cephalostat attached to the wall, with the ear rods passively adapted in their external auditory canal. For standardization of photographs, patients were asked to look at an inclined mirror, with natural head position ${ }^{8,20,23}$. An umbrella flash with tripod positioned behind the camera was used. A light box was placed behind the patient to avoid shadows on the photographs. In addition, a nylon wire connected to a metal weight was adapted to the light box to represent the true vertical line and help in trimming of photographs, to avoid wrong inclination of the profile in relation to the ground.

Photographs were prepared and edited in a standardized manner using an image-editing software (Adobe Photoshop $^{\circledR}$; Adobe Systems Inc., San Jose, CA, USA) (Figure 6). Photographs were organized using Microsoft PowerPoint software (Microsoft Corporation. Redmond, WA, USA) for individual visualization on a computer screen. Only the lateral facial photographs were subjectively evaluated by five orthodontists experienced with the treatment of patients with cleft lip and palate, belonging to the HRAC/USP rehabilitation team. No examiner was previously calibrated for evaluation of photographs. The examiners were asked to evaluate the photographs and

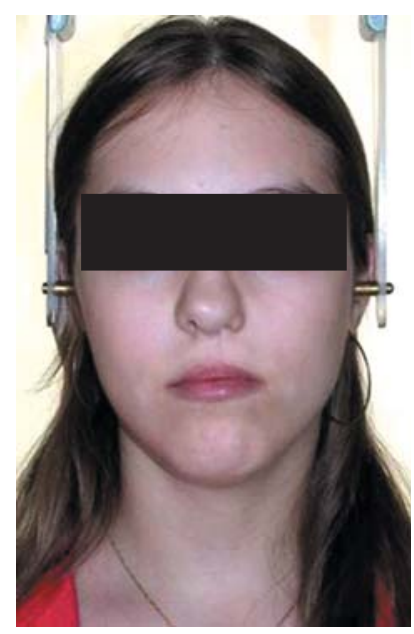

A

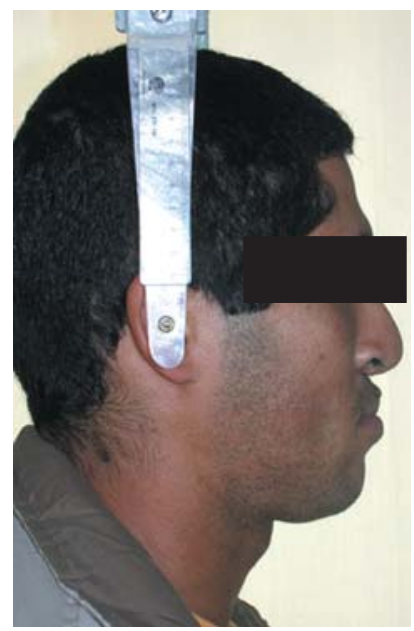

C

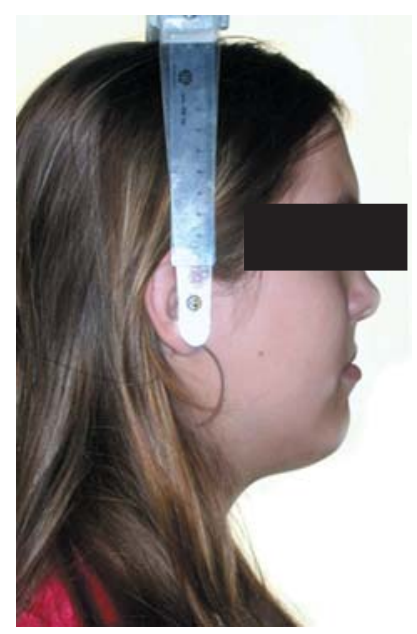

B

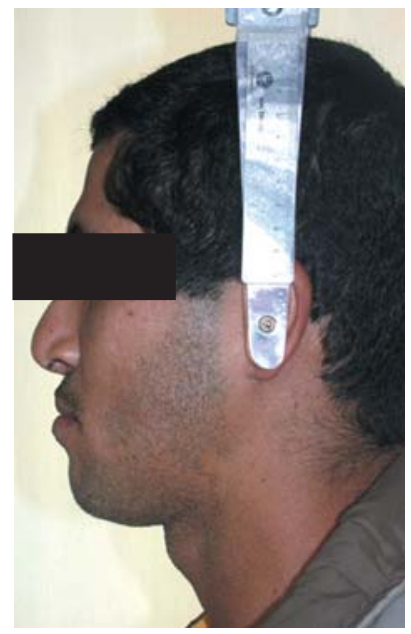

D
FIGURE 3- Patients with cleft lip and palate. Facial analysis in unilateral (A and B) and bilateral (C and D) cleft lip and palate in adult patients, operated at conventional ages and rehabilitated at HRAC/USP. Nasomaxillary deficiency reveals the negative influence of primary plastic surgeries on the face on a long-term basis

TABLE 1- Compilation of the studied population: patients with complete and incomplete cleft palate distributed according to gender and operated or unoperated conditions

\section{Total sample}

85 patients

\begin{tabular}{|c|c|c|c|}
\hline \multicolumn{2}{|c|}{ Operated patients } & \multicolumn{2}{|c|}{ Unoperated patients } \\
\hline \multicolumn{2}{|c|}{$50(58.82 \%)$} & \multicolumn{2}{|c|}{$35(41.18 \%)$} \\
\hline Male & Female & Male & Female \\
\hline $10 \rightarrow(20 \%)$ & $40 \rightarrow(80 \%)$ & $12(34.29 \%)$ & $23(65.71 \%)$ \\
\hline
\end{tabular}




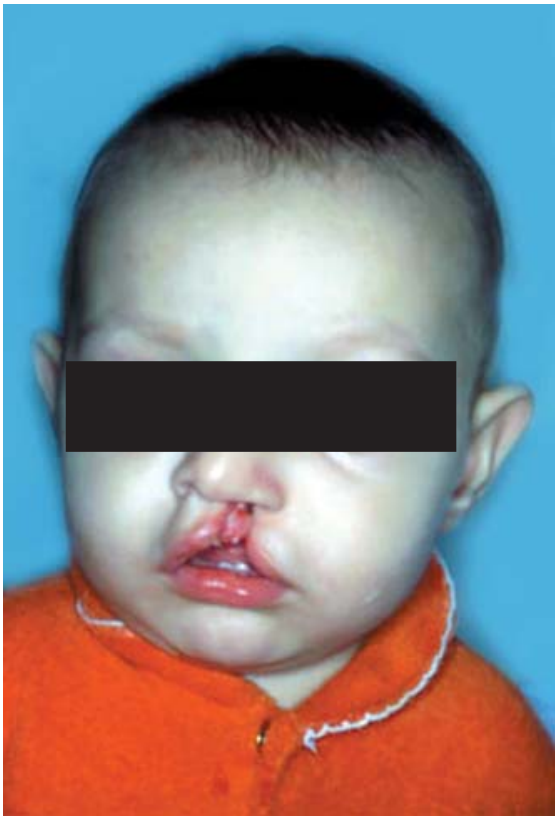

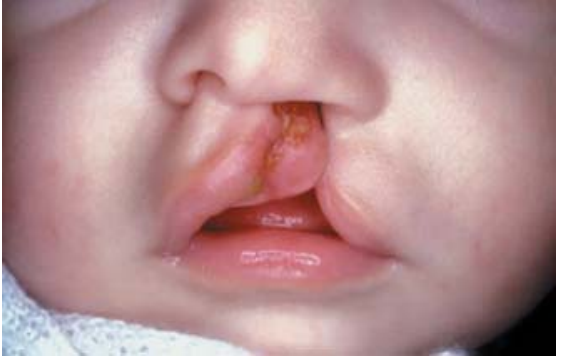

B

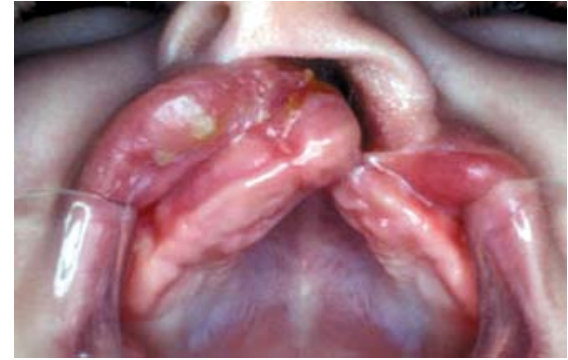

C

A

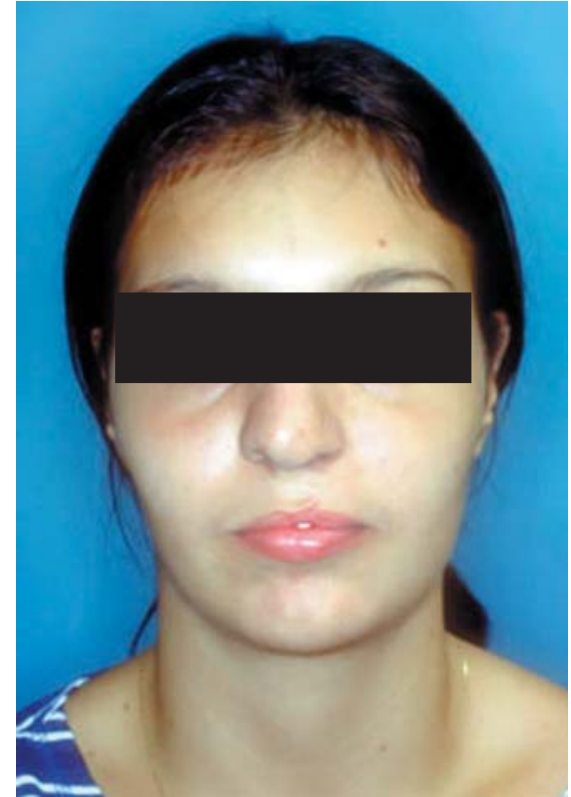

D

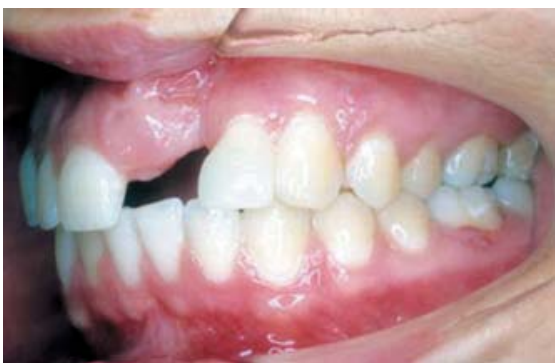

G

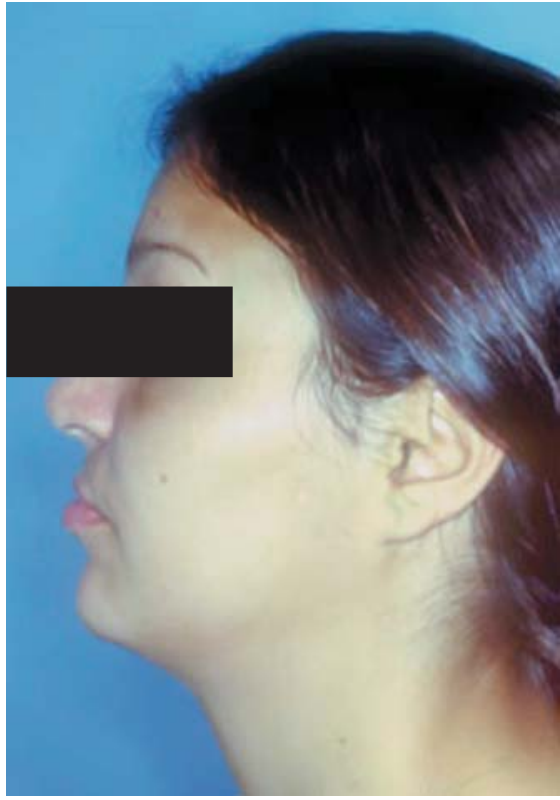

$\mathbf{E}$

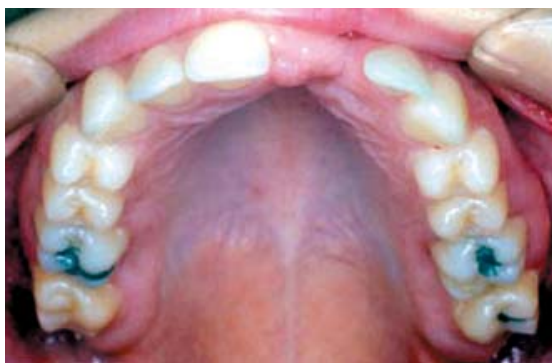

H

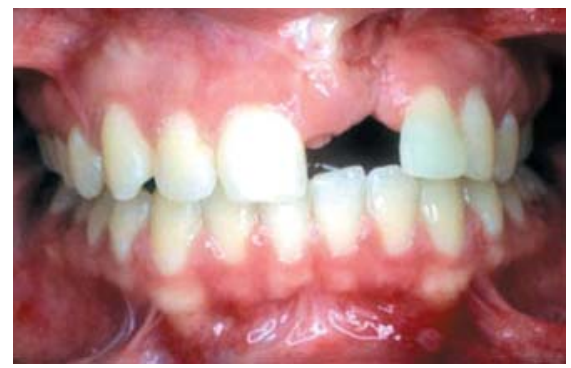

$\mathbf{F}$

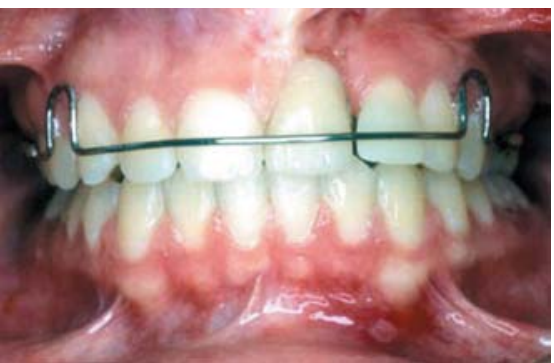

I

FIGURE 4- Patient with cleft lip and alveolus. A) to C) complete unilateral cleft lip and alveolus. D) and E) facial analysis in adulthood after rehabilitation at HRAC/USP demonstrating that the maxilla is well positioned in the face (Pattern I). F) to I) intraoral views after rehabilitation at HRAC/USP 
assign the scores 'esthetically pleasant' or 'esthetically unpleasant' for zygomatic projection and nasolabial angle, and scores 'Pattern I', 'Pattern II' and 'Pattern III' for overall facial analysis ${ }^{6}$. In Pattern I, the maxilla and mandible are well positioned to each other and compose a harmonious face $^{6}$. Pattern II is characterized by positive sagittal relationship between the maxilla and mandible, due to

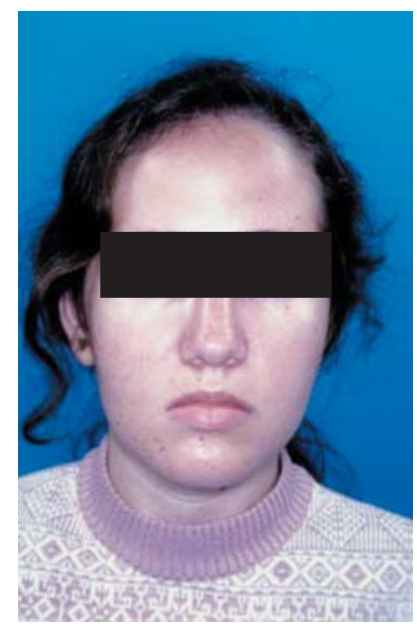

A

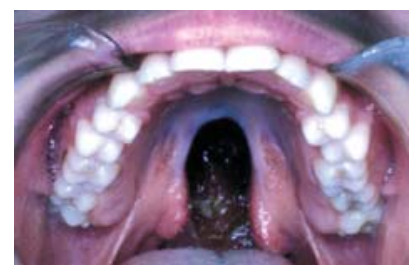

C

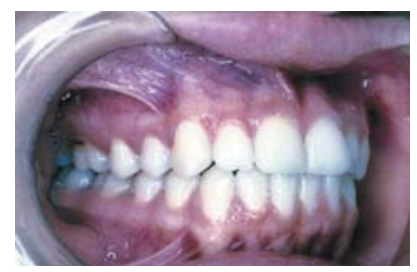

E

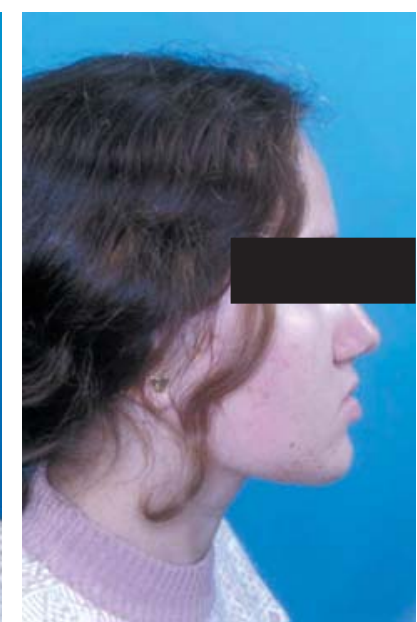

B

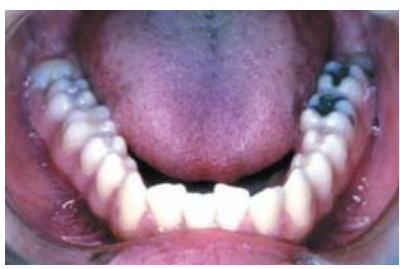

D

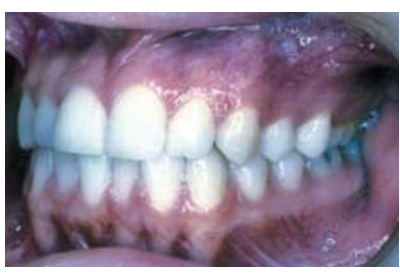

$\mathbf{F}$
FIGURE 5- Patient with isolated cleft palate. Frontal and lateral facial analyses and occlusal analysis of adult patient with isolated cleft palate not previously rehabilitated. The alveolar integrity, which favors the establishment of normal occlusion, is characteristic of isolated cleft palate. The cleft does not affect the alveolar ridge. If complete, it reaches the incisive foramen, preserving the alveolar ridge maxillary dental protrusion and/or mandibular deficiency ${ }^{6}$. Pattern III presents negative sagittal relationship between the maxilla and mandible, due to mandibular prognathism and/or maxillary deficiency ${ }^{6}$.

Examiners received a form with corresponding spaces for diagnosis of zygomatic projection, nasolabial angle and facial pattern.

For comparison between groups, the individual result of each patient was obtained by the mean score of 5 examiners using the chi-square statistical test ${ }^{10,15}$. All tests were performed at a significance level of $5 \%$.

\section{RESULTS}

The method employed for facial diagnosis was subjective, comprising only qualitative analysis of the face by clinical observation. Kappa statistics was applied to establish the inter-examiner agreement and reliability of the method. The mean kappa values ranged from 0.31 in evaluation of zygomatic projection, and 0.34 in evaluation of nasolabial angle to 0.63 in evaluation of facial pattern. Descriptive statistics and application of the chi-square statistical test are presented in Tables 2, 3 and 4.

Regarding the nasolabial angle (Table 2), 69.41\% of the total sample was scored as pleasant (score 1) whereas $30.59 \%$ was scored as esthetically unpleasant (score 2). Comparison of the groups of unoperated and operated patients revealed that $68.57 \%$ of unoperated patients received score 1 and $31.43 \%$ received score 2 , compared to $70 \%$ and $30 \%$ for operated patients, respectively. The chisquare test did not reveal significant difference $(p>0.05)$ for the nasolabial angle between operated and unoperated groups.

In relation to zygomatic projection (Table 3), $80 \%$ of the total sample presented good zygomatic projection (score 1) and $20 \%$ exhibited zygomatic deficiency (score 2). Comparing the operated and unoperated groups, $91.43 \%$ of unoperated patients were scored as pleasant and $8.57 \%$ as unpleasant, whereas in the group of operated patients $72 \%$ were scored as pleasant and $28 \%$ as unpleasant. Application of the chi-square test revealed a $p$ value of 0.028 , demonstrating significant difference between groups of operated and unoperated patients as to zygomatic projection.

Evaluation of facial pattern (Table 4) demonstrated that $54.12 \%$ of the total sample presented Pattern I, 32.94\%

TABLE 2- Statistics of evaluation of the nasolabial angle

\begin{tabular}{llll}
\hline Nasolabial angle & Pleasant & Unpleasant & Total \\
\hline Unoperated & $24(68.57 \%)$ & $11(31.43 \%)$ & $35(100 \%)$ \\
Operated & $35(70 \%)$ & $15(30 \%)$ & $50(100 \%)$ \\
Total & $59(69.41 \%)$ & $26(30.59 \%)$ & $85(100 \%)$ \\
\hline
\end{tabular}

$x^{2}=0.02 ; p=0.888$ non significant. 


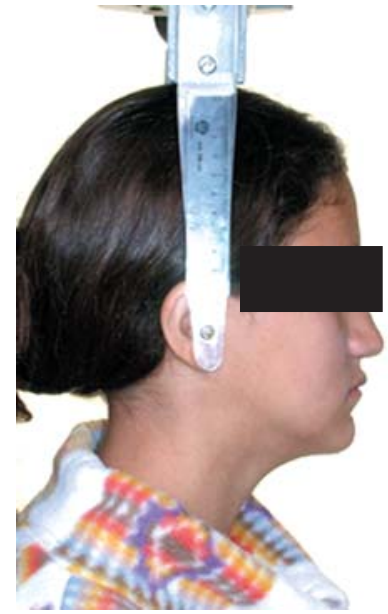

A

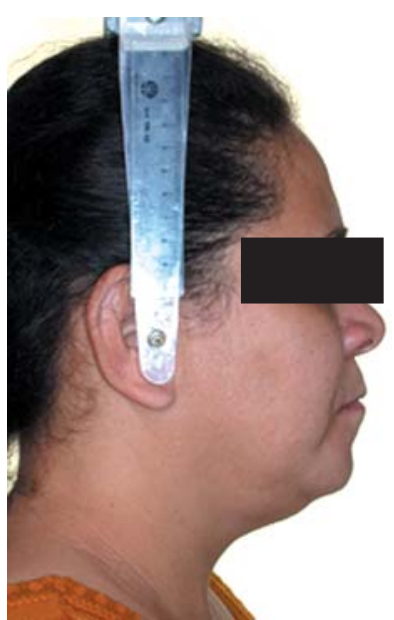

$E$

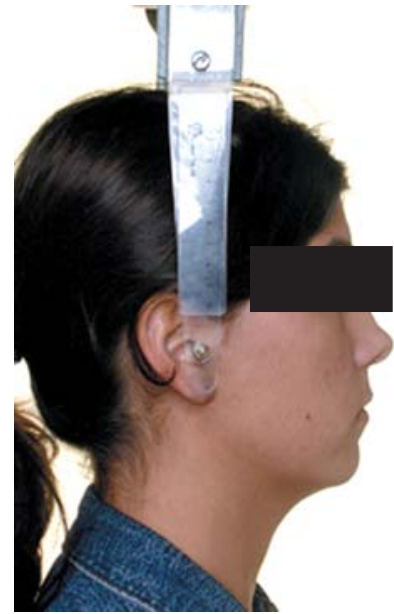

B

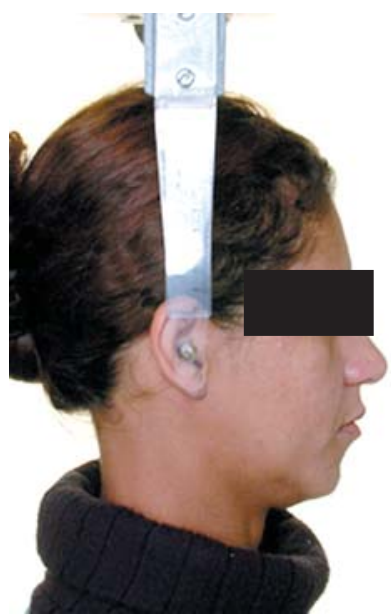

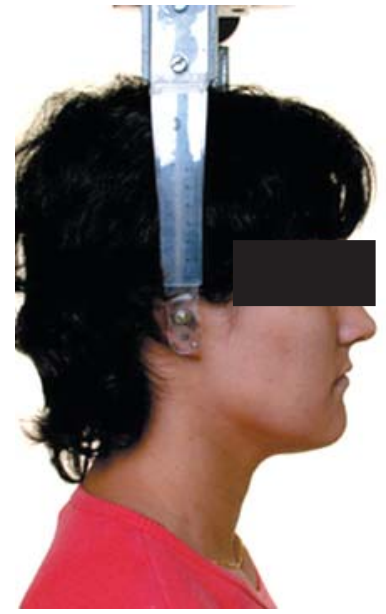

C

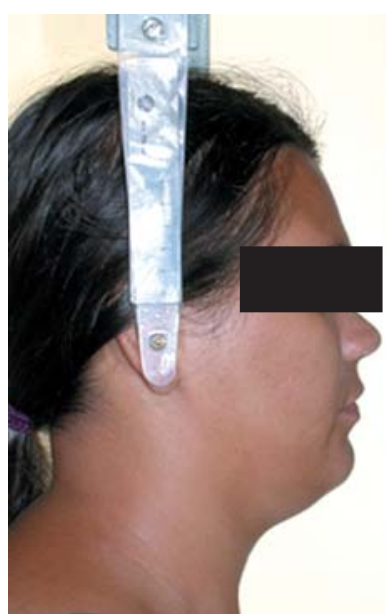

G

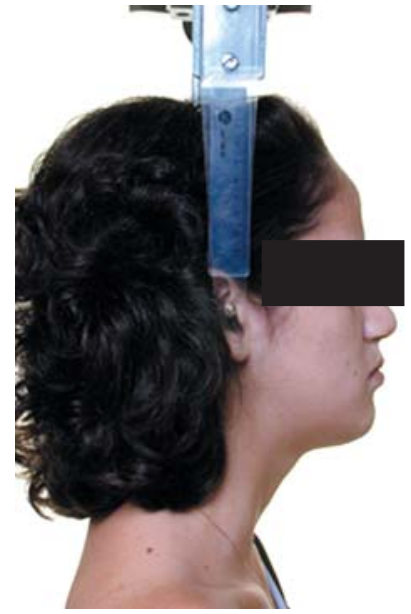

D

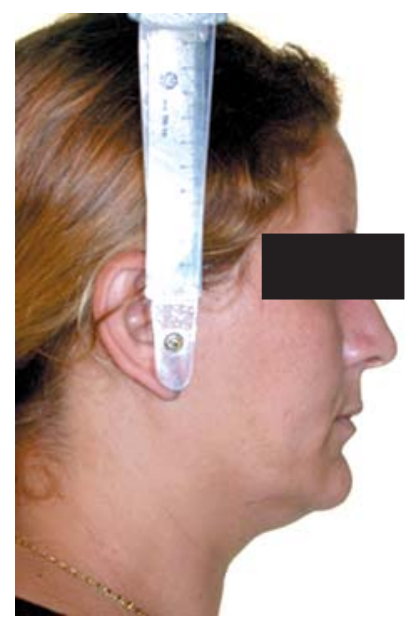

H

FIGURE 6- Patients selected from the sample of 85 patients with isolated cleft palate. A) to D) adult patients operated at conventional ages. E) to $\mathrm{H}$ ) unoperated adult patients

TABLE 3- Statistics of evaluation of the zygomatic projection

\begin{tabular}{llll}
\hline Zygomatic projection & Pleasant & Unpleasant & Total \\
\hline Unoperated & $32(91.43 \%)$ & $3(8.57 \%)$ & $35(100 \%)$ \\
Operated & $36(72 \%)$ & $14(28 \%)$ & $50(100 \%)$ \\
Total & $68(80 \%)$ & $17(20 \%)$ & $85(100 \%)$ \\
\hline
\end{tabular}

$x^{2}=4.86 ; p=0.028$ statistically significant.

TABLE 4- Statistics of evaluation of the facial pattern

\begin{tabular}{|c|c|c|c|c|}
\hline Facial pattern & Pattern I & Pattern II & Pattern III & Total \\
\hline Unoperated & $19(54.29 \%)$ & $13(37.14 \%)$ & $3(8.57 \%)$ & 35 (100\%) \\
\hline Operated & 27 (54\%) & $15(30 \%)$ & $8(16 \%)$ & $50(100 \%)$ \\
\hline Total & $46(54.12 \%)$ & 28 (32.94\%) & $11(12.94 \%)$ & $85(100 \%)$ \\
\hline
\end{tabular}

$x^{2}=1.20 ; p=0.550$ non significant. 
Pattern II and 12.94\% Pattern III. Comparison of groups of operated and unoperated patients revealed that $54.29 \%$ of unoperated patients exhibited Pattern I, 37.14\% Pattern II and $8.57 \%$ Pattern III, compared to 54\%, 30\% and 16\% for operated patients, respectively. The chi-square test did not reveal a significant $p$ value. Consequently, there was no statistically significant difference $(p>0.05)$ in the facial pattern between operated and unoperated patients.

\section{DISCUSSION}

The functional implications of cleft palate on speech and hearing are well known by professionals experienced with this condition because they represent a highly characteristic functional status. Patient rehabilitation is initiated early ${ }^{7}$ with palate reconstruction to allow full functional performance of the velopharyngeal sphincter ${ }^{19}$ and auditory tube ${ }^{19,21}$. Thus, the primary goal of palatoplasty is function. However, the typical facial morphology observed in isolated cleft palate is not well defined, and it is unknown whether plastic surgery has some influence on it on a longterm basis. From a cephalometric standpoint, individuals with isolated cleft palate present a retrognathic mature face, yet with acceptable sagittal relationship between bone bases $^{4,9,25}$ and vertical mandibular morphology, regardless of previous therapeutic approaches s,3,9,26. $^{\text {. }}$

The present study evaluated the face clinically, by accomplishment of facial analysis on standardized lateral photographs (Figure 6). A total of 85 post-adolescent patients with isolated cleft palate were evaluated for establishment of facial morphology. Two references were used for definition of maxillary positioning in the face, namely nasolabial angle and zygomatic projection. Mandibular positioning was inferred by analysis of facial pattern ${ }^{6}$.

For evaluation of the nasolabial angle, the five examiners responded to a questionnaire based on facial analysis, with two options: esthetically pleasant or esthetically unpleasant nasolabial angle. Results are presented on Table 2. Score 1 was assigned to nearly $69 \%$ of evaluations of the nasolabial angle, which demonstrates that for the majority of examiners it was esthetically pleasant. Therefore, most evaluations revealed a nasolabial angle compatible with lateral facial esthetics. This indicates good sagittal position of the maxilla or maxillary dentoalveolar portion. No statistically significant difference was found in the comparison of evaluations between operated and unoperated patients, thereby indicating that palatoplasty does not interfere with the nasolabial angle. In summary, maxillary positioning in operated and unoperated patients with isolated cleft palate tends to be good, according to the evaluation of the nasolabial angle. Figure 6 depicts the statistics by demonstrating that operated and unoperated patients cannot be distinguished on the basis of evaluation of the nasolabial angle.

The tendency of maxillary retrognathism, cephalometrically revealed by the SNA and SN.ENA angles ${ }^{3,4,9,25-27}$, did not influence the nasolabial angle. This means that the maxilla is clinically well positioned in the face in relation to the cranial base. This reduction in maxillary cephalometric measurements may be at least partly explained by the cranial base inclination.

An unpleasant nasolabial angle was observed in approximately $30 \%$ of patients, mainly due to closure of this angle (in nearly 68\%). The reduction in nasolabial angle was assigned to soft tissue alterations, such as lip vermillion turned inside out or lowering of the nasal apex, and occasionally to probable dental protrusion. Few patients (32\%) were defined as having an open nasolabial angle, assigned to retrusion of maxillary teeth or upward inclination of the nasal apex. This indicates that the alteration in nasolabial angle was to a large extent related to soft tissue, lip and nose, rather than to the dentoalveolar complex, which allows the conclusion that patients with isolated cleft palate present a well positioned maxilla from a clinical standpoint.

Results of zygomatic projection are presented on Table 3. This reference reinforces the diagnosis of the nasolabial angle because it allows determining the maxillary sagittal position. The results of 5 examiners for this structure were better than those observed for the nasolabial angle as zygomatic projection was scored as esthetically pleasant in $80 \%$ of the cases. This outcome demonstrates that the maxilla is well positioned in the face according to evaluation of zygomatic projection and may be confirmed by the photographs shown on Figure 6. Table 3 shows that the zygomatic projection was scored as esthetically unpleasant in only $20 \%$ of cases, indicating maxillary retrusion. Statistics reveal that cleft palate had only a mild influence on zygomatic projection.

There was difference in evaluation of zygomatic projection between operated and unoperated patients (Table 3). Zygomatic deficiency was more frequent in operated patients, affecting nearly $28 \%$ of them. This smaller zygomatic projection in operated patients suggests an influence from palatoplasty compared to unoperated patients. In the unoperated group, 91\% of patients exhibited good zygomatic projection versus $72 \%$ of patients in the operated group. The difference between the nasolabial angle and zygomatic projection between operated and unoperated patients may be explained by the inherent subjectivity of the method, namely clinical evaluation of the face.

An especially interesting aspect revealed by both clinical references used for evaluation of the maxillary sagittal position in the face, i.e., nasolabial angle and zygomatic projection, was that, on the average, the maxilla was not influenced by the presence of cleft palate, at least as a general rule. This means that there seems not to be a typical maxillary sagittal position in isolated cleft palate. The little diversity in maxillary sagittal positioning, diagnosed by evaluation of the nasolabial angle and zygomatic projection, may be observed in non-cleft individuals. This finding indicates that this is part of the variability of maxillary positioning in mankind.

The surprising fact was the observation that accomplishment of palatoplasty in childhood may influence the anteroposterior maxillary positioning in the face, 
according to evaluation of zygomatic projection. This was not an expected outcome because it has not been proved elsewhere by another methodology or cephalometrics ${ }^{26}$, nor demonstrated for the nasolabial angle; $8.5 \%$ of unoperated patients presented zygomatic deficiency, compared to $28 \%$ of operated patients.

The remarkable postoperative morphological changes observed in cleft lip and palate $e^{5,7}$, which re-design the maxilla over growth, do not impair the maxillary esthetics in cleft palate. The partial discontinuity of the maxilla, affecting only the secondary palatal prominences, assigns stability of sagittal positioning of the maxilla along growth, which is not observed in clefts affecting the primary and secondary palates. This characteristic of the maxilla distinguishes isolated cleft palate from complete cleft lip and palate, in which there is midface retrusion in adult patients due to repair plastic surgeries and maxillary segmentation throughout its structure, as observed on Figure 3, illustrating unilateral (Figure 3A) and bilateral (Figure 3B) complete cleft lip and palate. In complete cleft lip and palate, the therapeutic process may partly fail due to restriction of nasomaxillary growth potential in all three directions.

If the maxilla tends to keep a normal sagittal position in patients with isolated cleft palate, the question is: which is the mandibular positioning? Lateral facial analysis was performed to answer that question in order to establish the facial skeletal outcomes, especially the mandibular position, based on the concept of facial pattern ${ }^{6}$. Considering the sagittal relationship between the bone bases, the face was scored as Pattern I, Pattern II and Pattern III ${ }^{6}$. In Pattern I, the maxilla and mandible are well positioned to each other and compose a harmonious face ${ }^{6}$. Pattern II is characterized by positive sagittal relationship between the maxilla and mandible, due to maxillary dental protrusion and/or mandibular deficiency ${ }^{6}$. Pattern III presents negative sagittal relationship between the maxilla and mandible, due to mandibular prognathism and/or maxillary deficiency, thus giving rise to a straight or concave facial profile ${ }^{6}$.

Data of lateral facial analysis are displayed on Table 4. According to the evaluations of examiners, 54\% of all patients presented Pattern I, which indicates good relationship between the maxilla and mandible. In fact, this coincides with cephalometric evaluation of the face in cleft palate. Cephalometric data reveal a reduction in distances representing the cranial base, maxillary and mandibular length; however, the relationship between the bone bases has been considered good, despite the facial retrusion ${ }^{4,9,25}$.

Thirty three percent of patients presented Pattern II, which suggests mandibular deficiency. This is a considerable percentage, though lower than expected. Since deficient mandibular growth in embryonic life is one of the etiological factors presented for the occurrence of cleft palate, due to the difficulty of elevation of palatal prominences at the right period, mandibular deficiency is expected in patients with cleft palate. Mandibular deficiency may be more representative in patients with Pierre Robin sequence ${ }^{17}$. The sample evaluated in the present study did not present any syndromes. An attempt was made to include only individuals with isolated cleft palate without syndromes. Thirteen percent of patients exhibited Pattern III, indicating mandibular prognathism and/or maxillary retrognathism.

The facial pattern was not influenced by the primary palatoplasty performed in childhood (Table 4). There was a higher frequency of Pattern III among operated patients despite the lower frequency of Pattern II, yet without statistical significance. In the unoperated group, nearly 8.5\% of patients presented Pattern III, compared to $16 \%$ among operated patients. These important data should be further investigated.

\section{CONCLUSION}

According to the results of the present study it may be concluded that, on the average, maxillary positioning in the face tended to be good, as demonstrated by evaluation of the nasolabial angle and zygomatic projection. Moreover, facial analysis revealed that the maxilla was not influenced by palatoplasty performed during childhood. The facial pattern was not influenced by primary palatoplasty, and intermaxillary relationship was considered satisfactory.

\section{REFERENCES}

1- Bishara SE. Cephalometric evaluation of facial growth in operated and non-operated individuals with isolated clefts of the palate. Cleft Palate J. 1973;10:239-46.

2- Bishara SE, Enemark H, Tharp RF. Cephalometric comparasions of the results of the Wardill-Kilner and Von Langenbeck palatoplasties. Cleft Palate J. 1976;13:319-29.

3- Bishara SE, Inversen WW. Cephalometric comparisons on the cranial base and face in individuals with isolated clefts of the palate. Cleft Palate J. 1974;11:162-75.

4- Bishara SE. The influence of palatoplasty and cleft length on facial development. Cleft Palate J. 1973;10:390-8.

5- Capelozza L Filho, Cavassan AO, Silva OG Filho. Avaliação do crescimento craniofacial em portadores de fissura transforame incisivo unilateral: estudo transversal. Rev Bras Cir. 1987;77:97-106.

6- Capelozza L Filho. Diagnóstico em ortodontia. Maringá: Dental Press; 2004.

7- Capelozza L Filho, Silva OG Filho. Abordagem interdisciplinar no tratamento das fissuras labiopalatinas. In: Mêlega JC, editor. Cirurgia plástica fundamentos e arte: cirurgia reparadora da cabeça e pescoço. Rio de Janeiro: Medsi; 2002. p. 59-88.

8- Cooke MS, Wei SH. The reproducibility of natural head posture: a methodological study. Am J Orthod Dentofacial Orthop. 1988;93:2808.

9- Dahl E. Craniofacial morphology in congenital clefts of the lip and palate: an x-ray cephalometric study of young adult males. Acta Odontol Scand. 1970;28(Suppl 57):11-167.

10- Fleiss JL. Statistical methods for rates and proportions. New York: Wiley; 1973. 
11- Heliövaara A, Haapanen ML, Hukki J, Ranta R. Long-term effect of pharyngeal flap surgery on craniofacial and nasopharyngeal morphology in patients with cleft palate. Acta Odontol Scand. 2003;61:159-63.

12- Jolleys A. A review of the results of operations on cleft palates with reference to maxillary growth and speech function. Br J Plast Surg. 1954;7:229-41.

13- Kaartinen V, Voncken JW, Shuler C, Warburton D, Bu D, Heisterkamp N, et al. Abnormal lung development and cleft palate in mice lacking TGF-beta 3 indicates defects of epithelial-mesenchymal interaction. Nat Genet. 1995;11:415-21.

14- Karsten A, Larson M, Larson O. Dental occlusion after VeauWardill-Kilner versus minimal incision technique repair of isolated clefts of the hard and soft palate. Cleft Palate Craniofac J. 2003;40:504-10.

15- Landis JR, Koch GG. The measurement of observer agreement for categorical data. Biometrics. 1977;33(1)159-74.

16- MacCollum DW, Richardson SO, Swanson LT. Habilitation of the cleft-palate patient. N Engl J Med. 1956;254(7):299-307.

17- Marques IL, Barbieri MA, Bettiol H. Etiopathogenesis of isolated Robin sequence. Cleft Palate Craniofac J. 1998;35(6):517-25.

18- Miettinen PJ, Chin JR, Shum L, SlavKin HC, Shuler CF, Derynck $\mathrm{R}$, et al. Epidermal growth factor receptor function is necessary for normal craniofacial development and palate closure. Nat Genet. 1999;22(1):69-73.

19- Migliorucci RR. Análise das características da fala de indivíduos fissurados de palato operados [monografia]. Bauru (SP): Hospital de Reabilitação de Anomalias Craniofaciais, Universidade de São Paulo; 2004 .

20- Peng L, Cooke MS. Fifteen-year reproducibility of natural head posture: a longitudinal study. Am J Orthod Dentofacial Orthop. 1999;116(1):82-5.

21- Piazentin SHA. A influência da palatoplastia primária nas alterações do ouvido médio [dissertação]. São Paulo (SP): Pontifícia Universidade Católica de São Paulo; 1989.

22- Qiu M, Bulfone A, Ghattas I, Meneses JJ, Christensen L, Sharpe $\mathrm{PT}$, et al. Role of the D1x homeobox genes in proximodistal patterning of the branchial arches: mutations of D1x-1, D1x-2, and D1x-1 and -2 alter morphogenesis of proximal skeletal and soft tissue structures derived from the first and second arches. Dev Biol. 1997;185(2):16584

23- Rino J Neto, Freire-Maia BAV, Paiva JB. Método de registro da posição natural da cabeça para obtenção da radiografia cefalométrica lateral: considerações e importância do método no diagnóstico ortodôntico cirúrgico. Rev Dent Press Ortodon Ortopedi Facial. 2003;8(3):61-71.

24- Satokata I, Maas R. Msx 1 deficient mice exhibit cleft palate and abnormalities of craniofacial and tooth development. Nat Genet.1994;6(4):348-56.

25- Shibasaki Y, Ross RB. Facial growth in children with isolated cleft palate. Cleft Palate J.1969;6:290-302.

26- Silva OG Filho, Cavassan AO, Normando ADC. Influência da palatoplastia no padrão facial de pacientes portadores de fissura pósforame incisivo. Rev Bras Cirur. 1989;79(6):315-22.

27- Silva OG Filho, Cavassan AO, Sampaio LL. Avaliação do padrão cefalométrico em pacientes portadores de fissura pós-forame incisivo não operado. Rev Bras Cir. 1989;79(3):137-47.
28- Silva OG Filho, Rocha R, Capelozza L Filho. Padrão facial do paciente portador de fissura pré-forame incisivo unilateral completa. Rev Bras Cir. 1989;79(4):197-205.

29- Zhao X, Zhang Z, Song Y, Zhang X, Zhang Y, Hu Y, et al. Transgeneically ectopic expression of Bmp4 to the Msx1 mutant dental mesenchyme restores downstream gene expression but represses Shh and Bmp2 in the enamel knot of wild type tooth germ. Mech Dev. 2000;99(1-2):29-38. 